\title{
Pengaruh Pemberian Air Jeruk Lemon Terhadap Kualitas Produk Nata de Coco
}

\author{
Sri Wahyuni \\ Universitas Muslim Nusantara Al Wasliyah \\ sriwahyuni@umnaw.ac.id
}

\begin{abstract}
ABSTRAK
Penelitian ini bertujuan untuk mengetahui pengaruh konsentrasi air Jeruk Lemon terhadap kualitas Nata de coco juga sebagai pengganti cuka dan pemberi aroma terhadap kualitas nata de coco. Penelitian ini menggunakan metode Rancangan Acak Lengkap (RAL) yang terdiri atas 4 perlakuan dengan konsentrasi $(0 \%, 2 \%, 4 \%$ dan $6 \%)$ dan 3 ulangan. Parameter yang diamati adalah ketebalan, kadar serat, keasaman (PH), dan uji organoleptik. Hasil Hasil penelitian yang diperoleh kemudian dianalisis dengan ANAVA dan uji lanjut DMRT pada taraf 5\%. Hasil penelitian menunjukkan bahwa air jeruk nipis memberikan pengaruh nyata terhadap ketebalan, kadar serat kasar, keasaman $(\mathrm{pH})$ dan uji organoleptik. Perlakuan terbaik adalah pada perlakuan konsentrasi air jeruk nipis $2 \%$ yang menghasilkan ketebalan $0,93 \mathrm{~cm}$, kadar serat kasar $1,98 \%$, keasaman $(\mathrm{pH})$ 4,42 dan organoleptik tekstur, warna,dan tingkat kesukaan terbaik.
\end{abstract}

Kata Kunci : Pengaruh, Air Jeruk Lemon, Kualitas Produk Nata De Coco

\begin{abstract}
This study aims to determine the effect of Lemon Lemon water concentration on the quality of Nata de coco as well as a substitute for vinegar and aroma giving to the quality of nata de coco. This study uses a completely randomized design (CRD) method consisting of 4 treatments with concentrations $(0 \%, 2 \%, 4 \%$ and $6 \%)$ and 3 replications. The parameters observed were thickness, fiber content, acidity $(\mathrm{PH})$, and organoleptic test. Results The results obtained were then analyzed with ANAVA and DMRT follow-up tests at the 5\% level. The results showed that lime juice had a significant effect on thickness, crude fiber content, acidity $(\mathrm{pH})$ and organoleptic tests. The best treatment is the treatment of $2 \%$ concentration of lime juice which produces $0.93 \mathrm{~cm}$ thickness, $1.98 \%$ crude fiber content, acidity (pH) 4.42 and the best organoleptic texture, color, and preference level..
\end{abstract}

Keywords : Influence, Lemon Orange Water, Quality of Nata De Coco Products. 


\section{PENDAHULUAN}

\section{Latar Belakang}

Nata merupakan produk makanan yang berasal dari Filipina. Jenis makanan ini diperoleh melalui proses fermentasi dengan bentuk seperti agar dan bertekstur kenyal. Nata merupakan produk pangan yang relatif baru diperkenalkan di Indonesia tetapi produk ini sudah dikenal cukup luas oleh masyarakat terutama kalangan ekonomi menengah ke atas. Nata dihasilkan oleh suatu spesies bakteri penghasil asam asetat yaitu Acetobacter xylinum. Bakteri tersebut dapat membentuk polikel tebal di atas permukaan medium, polikel tebal itu disebut nata. Di pasaran nata dijual sebagai makanan dalam berbagai bentuk, diantaranya nata dalam sirup, pencampuran es krim, pencampuran koktail buah, kue dan makanan ringan lainnya. Permintaan produk nata baik untuk pasaran dalam negeri maupun ekspor cukup besar, sampai saat ini peluang pasarnya masih terbuka luas. Penyediaan nata masih dibawah permintaan sementara upaya produksi nata secara besar-besaran belum dilakukan, melainkan masih terbatas pada skala industri rumah tangga. Produk yang dihasilkannya pun masih dipasarkan secara lokal untuk memenuhi permintaan para pengusaha makanan. Perusahaan makanan dan minuman biasa meminta nata dalam bentuk lembaran mentah hasil fermentasi, kemudian oleh mereka diolah menjadi bentuk yang siap dikonsumsi. Permasalahan dari Produksi Nata de Coco yang dihasilkan dalam proses fermentasi dan pemanenan yaitu aroma yang kurang sedap dari hasil fermentasi karena penggunaan asam cuka. Sehingga diperlukan penggolahan yang lebih lama dan perebusan yang berulang-ulang hingga aroma menyengat pada nata hilang. Perlunya pengganti cuka dengan air jeruk lemon dalam pembuatan nata de coco. Air jeruk lemon sebagai pengganti asam cuka biasa digunakan dalam pembuatan nata. Air jeruk lemon memiliki suasana asam dan aroma yang khas sehingga diharapkan nata yang dihasilkan akan memiliki aroma yang lebih khas dengan penanganan pasca panen yang lebih praktis.

\section{Perumusan Masalah}

Dalam pengolahanya sering diberi pemanis dan essens berbagai aroma untuk menghilangkan aroma menyengat pada Nata De Coco. Menurut Anhar Fajrien Iryandi, dkk (2014) pembuatan nata dengan penambahan asam cuka ini menimbulkan aroma menyengat yang kurang sedap, sehingga memerlukan tindakan lanjut pasca pemanenan nata yaitu dengan perendaman dan perebusan yang berulang-ulang.

\section{Tujuan Penelitian}

Tujuan penelitian ini adalah :

Untuk mencari solusi pemecahan masalah dalam menghilangkan aroma menyengat pada Nata de Coco.

\section{Manfaat Penelitian}

Manfaat yang dapat diambil dari penelitian ini sebagai berikut:

1. Bagi peneliti menjadi sumber pengalaman yang baik dalam menemukan solusi pemecahan masalah dalam mengatasi bau menyengat pada Nata De Coco

2. Menemukan teknik pengolahan Nata De Coco yang baik dan praktis

3. Bagi peneliti lain dan masyarakat umum, hal ini dapat menjadi sumber literatur dalam proses pengembangan dalam teknik pengolahan Nata De Coco berikutnya. 


\section{Kajian Literatur \\ 1. Keasaman (pH)}

Pengukuran Keasaman $(\mathrm{pH})$ sangat penting karena merupakan salah satu faktor dalam pembentukan nata mempengaruhi pertumbuhan dan kerja enzim pada bakteri Acetobacter xylinum yang menentukan kualitas dari nata de coco. Keasaman $(\mathrm{pH})$ nata de coco pada berkisar antara 3,54-5,02. Hasil perhitungan $\mathrm{pH}$ berpengaruh pada perhitungan ANAVA maka dilanjutkan DMRT 5\% hasil masing-masing perlakuan menunjukkan beda nyata terhadap pemberian air jeruk lemon. Hasil rata-rata $\mathrm{pH}$ tertinggi diperoleh pada konsentrasi $0 \%$ yaitu sebesar 5,02 namun hasil nata yang dihasilkan berupa ketebalan dan kadar serat kasar tidak optimal. $\mathrm{pH}$ yang paling baik pada pemberian konsentrasi jeruk nipis $2 \%$ dengan nilai $\mathrm{pH} 4,55$ karena $\mathrm{pH}$ ini merupakan $\mathrm{pH}$ optimum dalam pembuatan nata dan menyebabkan pengaruh baik dalam kualitas nata. Hasil nata dari perlakuan pemberian air jeruk nipis pada konsentrasi $2 \%$ dengan $\mathrm{pH}$ 4,55 mempunyai ketebalan tertinggi dan kadar serat kasar tertinggi. Penurunan kenaikan $\mathrm{pH}$ mempengaruhi hasil ketebalan dan kadar serat nata de coco. Menurut Elga Malvianie, $d k k$. (2014) bakteri bisa tumbuh pada kisaran $\mathrm{pH}$ 3,5-7,5. Keasaman $(\mathrm{pH})$ terendah pada konsentrasi air jeruk nipis $6 \%$ dengan $\mathrm{pH}$ larutan nata 3,54. Penurunan $\mathrm{pH}$ pada nata menyebabkan hasil dari lembaran nata tipis dan kadar serat kasar yang rendah. Hal ini disebakan pengaruh penurunan $\mathrm{pH}$ pada penambahan konsentrasi air jeruk lemon. Semakin tinggi konsentrasi air jeruk nipis yang ditambahkan maka nilai ketebalan yang diperoleh semakin rendah. Hal ini disebabkan konsentrasi air jeruk lemon yang ditambahkan tinggi menyebabkan nilai $\mathrm{pH}$ larutan nata semakin rendah (semakin asam) sehingga proses pembentukan selulosa semakin rendah yang dikarenakan semakin jauhnya larutan dari $\mathrm{pH}$ optimum pembentukan nata.

\section{Kadar Serat Kasar Nata de Coco}

Serat pada nata terdiri dari 2 jenis yaitu serat larut yang larut air bersifat mengikat air dan serat tak larut berupa benang-benang selulosa yang disebut dengan serat kasar nata. Kadar serat kasar merupakan parameter yang dapat menentukan kualitas dari nata de coco.

Kadar serat nata de coco berkisar antara 1,23\% - 1,97\%. Hasil kadar serat kasar berpengaruh pada perhitungan ANAVA maka dilakukan uji lanjut DMRT 5\% hasil kadar serat kasar yang diperoleh masing-masing perlakuan menunjukkan beda nyata terhadap pemberian jeruk lemon. Konsentrasi air jeruk lemon 2\% mempunyai kadar serat tertinggi 1,97\%, tingginya kandungan kadar serat disebabkan nata yang terbentuk pada konsentrasi ini mempunyai ketebalan tertinggi sehingga sejalan dengan kandungan kadar serat kasar yang terbentuk. Persentase serat kasar yang tinggi dipengaruhi oleh aktivitas dari Acetobacter xylinum pada proses metabolisme glukosa menjadi selulosa. Hal ini dapat dilakukan apabila nutrien yang tersedia pada medium cukup. Banyaknya mikroorganisme yang tumbuh pada suatu media dipengaruhi oleh nutrisi yang terkandung pada media (Anhar Fajrien Iryandi, $d k k$. 2014). Proses pembentukan serat atau selulosa oleh bakteri Acetobacter xylinum merupakan suatu rangkaian proses biokimia. Mekanisme pembentukan selulosa bakteri nata. Glukosa melalui reaksi heksokinase menjadi glukosa-6-fosfat. Glukosa-6-fosfat diubah menjadi glukosa-1fosfat oleh enzim fosfoglukomutase. Reaksi selanjutnya adalah pembentukan uridin difosfat glukosa (UDP-glukosa) yang merupakan hasil reaksi antara glukosa-1-fosfat dengan uridin trifosfat (UTP), oleh kerja enzim glukosa-1-fosfaturidiltransferase. Reaksi ini dialihkan menuju kekanan kerja oleh pirofosfatase, yang menghidrolisa pirofosfat (PPi) menjadi ortofosfat (Pi). UDP-glukosa adalah donor langsung residu glukosa didalam pembentukan enzimatik selulosa oleh kerja selulosa sintase yang mengiatkan pemindahan residu glukosil dari UDP glukosa ke ujung non residu molekul selulosa (Lehninger. 1994 dalam Elga Malvianie, $d k k$. 2014). Secara keseluruhan kadar serat nata de coco pada pemberian air jeruk lemon pada konsentrasi 0\% - 6\% dengan anlisis kadar serat kasar 1,97\% - 1,23\% berada 
pada ketetapan atau kriteria Standar Nasional Indonesia SNI 01-4317-1996 kriteria kadar serat yang dihasilkan pada penelitian ini berada dibawah $4.5 \%$.

\section{Ketebalan Nata de Coco}

Berdasarkan hasil penelitian yang telah dilakukan diperoleh hasil pengukuran terhadap ketebalan nata de coco. Ketebalan pada nata de coco berkisar antara 0,23 cm -0,98 cm. Perhitungan ANAVA berpengaruh terhadap ketebalan nata maka dilanjutkan dengan uji DMRT 5\% yang didapatkan masing-masing perlakuan berbeda nyata terhadap pemberian air jeruk lemon. Hasil penelitian ketebalan tertinggi pada perlakuan konsentrasi air jeruk lemon $2 \%$ dihasilkan lembaran nata dengan ketebalan $0,93 \mathrm{~cm}$. Faktor nutrisi merupakan faktor paling penting dalam pertumbuhan bakteri yang mempengaruhi ketebalan dan pembentukan nata pada penelitian sumber karbon dan nitrogen pada setiap perlakuan sama yang dibedakan adalah faktor keasaman atau $\mathrm{pH}$ yang disebabkan oleh pengaruh pemberian air jeruk lemon dengan konsentrasi yang berbeda pada pembuatan nata sehingga menyebabkan perbedaan hasil yang didapatkan dalam penelitian. Perlakuan dengan pemberian konsentrasi air jeruk lemon $2 \%$ menyebabkan $\mathrm{pH}$ pada media nata 4,55 sudah optimum dalam pembentukan lembaran nata kerena menyebabkan hasil ketebalan yang lebih tinggi dibandingkan dengan hasil perlakuan lain. Hal ini diperkuat dengan pernyataan Saragih (2004), Acetobacter xylinum merupakan bakteri aerob pembentuk nata yang hidup pada media asam. Acetobacter xylinum dapat hidup dan berkembang pada $\mathrm{pH} 3-5$. Lembaran nata pada semua perlakuan termasuk kontrol (yang tidak diberi air jeruk lemon) dapat terbentuk karena faktor utama pertumbuhan bakteri Acetobacter xylinum terpenuhi berupa sumber karbon dan sumber nitrogen. Bakteri tetap membutuhkan air jeruk lemon atau cuka untuk $\mathrm{pH}$ yang optimum karena ketika larutan media nata de coco tidak diberikan air jeruk lemon ketebalan yang terbetuk tidak optimum, dalam penelitian ini perlakuan kontrol dengan konsentrasi jeruk nipis $0 \%$ ketebalan nata yang terbentuk sebesar $0,60 \mathrm{~cm}$ dan semakin menurun pada konsentrasi jeruk lemon $6 \%$ sehingga menghasilkan ketebalan paling rendah dengan ketebalan 0,23 cm. Hal ini perkuat oleh Anhar Fajrien Iryandi, $d k k$ (2014) konsenterasi air jeruk lemon yang ditambahkan tinggi menyebabkan nilai $\mathrm{pH}$ larutan nata semakin rendah (semakin asam) sehingga proses pembentukan lapisan nata semakin rendah

\section{METODE PENELITIAN \\ Lokasi dan Waktu Penelitian \\ Lokasi Penelitian}

Penelitian ini akan dilakukan di Fakultas Pertanian Universitas Muslim Nusantara Al Wasliyah Medan.

\section{Paramter Penelitian}

Parameter dalam penelitian ini meliputi ketebalan, kadar serat kasar, $\mathrm{pH}$ dan organoleptik nata de coco yang terdiri dari tekstur, warna, aroma, rasa dan tingkat kesukaan. Hasil penelitian diolah dengan perhitungan kuantitatif analisis varians (anava), jika terdapat beda nyata dilakukan uji lanjut DMRT pada taraf 5\%. Analisis data untuk uji organoleptik hasil nata de coco secara deskriptif dengan menilai produk nata de coco pada 12 sampel dengan dinilai oleh 10 panelis.

\section{Metode Penelitian}

Penelitian ini menggunakan metode eksperimen yang dilakukan menggunakan rancangan acak lengkap (RAL) dengan 4 perlakuan konsentrasi air jeruk lemon $(0 \%, 2 \%, 4 \%$ dan $6 \%)$ dan 3 ulangan sehingga diperoleh 12 rancangan percobaan 


\section{Prosedur Penelitian}

\section{Uji Organoleptik}

Uji organoleptik terdiri dari uji mutu hedonik dan uji hedonik dengan melibatkan 10 orang panelis. Uji mutu hedonik bertujuan untuk mengetahui kualitas nata yang diuji terhadap tekstur, warna, aroma dan rasa. Tekstur pada nata sangat mempengaruhi kesukaan konsumen terhadap produk tersebut. Nata merupakan makanan yang mudah digigit dan baik untuk pencernaan, mempunyai tekstur lembek hingga kenyal. Tekstur tertinggi diperoleh pada pemberian konsentrasi air jeruk nipis $2 \%$ dengan penilaian panelis 4,25 (agak kenyal hingga kenyal). Kekenyalan tekstur nata dipengaruhi oleh kadar serat kasar nata, perlakuan dengan konsentrasi $2 \%$ mempunyai kadar serat kasar yang tinggi dan juga ketebalan yang tinggi dibandingkan yang lain. Menurut Elga Malvianie, dkk. (2014) kadar selulosa total yaitu terkait dengan kandungan serat karena berdasarkan sifat serat mempunyai struktur yang rapat dan saling berikatan apabila lapisan selulosa semakin rapat disimpulkan bahwa sampel tersebut memiliki serat yang banyak dan semakin kenyal. Warna pada produk makanan merupakan salah satu faktor konsumen merasa tertarik atau tidak untuk memilih produk tersebut. Penilaian terhadap warna nata oleh panelis berdasarkan tabel 1 warna nata tertinggi diperoleh pada pemberian konsentrasi $2 \%$ dengan penilaian panelis 4,45 (agak putih hingga putih) disebabkan lembaran nata yang dihasilkan lebih tebal dari perlakuan yang lain sehingga warna nata tampak agak putih. Warna nata terendah pada konsentrasi air jeruk nipis 6\% dengan penilaian panelis 3,60 (putih kekuningan hingga agak putih). Aroma merupakan salah satu parameter yang menentukan rasa enak atau tidak dari suatu makanan. Konsumen akan menerima suatu bahan pangan jika mempunyai aroma yang baik. Berdasarkan hasil penilaian yang diberikan panelis Aroma tertinggi diperoleh pada pemberian konsentrasi air jeruk nipis 6\% dengan penilaian 4,69 (beraroma agak khas jeruk lemon hingga). Pemberiaan air jeruk lemon mempengaruhi aroma nata yang dihasilkan dimana semakin tinggi konsentrasi jeruk lemon menyebabkan aroma menyengat dan kurang sedap pada nata hilang dan dihasilkan aroma khas jeruk lemon. Aroma terendah diperoleh pada konsentrasi 0\% dengan nilai 2,80 (menyengat hingga khas nata). Aroma pada perlakuan konsentrasi 0\% disebabkan perlakuan ini tidak diberikan air jeruk lemon atau cuka. Namun, dihasilkan dari proses fermentasi nata merupakan penyebab aroma menyengat juga. Menurut penelitian Anhar Fajrien Iryandi, $d k k$. (2014) penambahan asam cuka ini menimbulkan aroma asam yang kurang sedap. Pemilihan suatu produk oleh konsumen selain melalui penilaian aroma dan warna adalah penilaian rasa. Rasa pada suatu produk menentukan produk itu disukai oleh konsumen atau tidak. Berdasarkan hasil penilaian panelis terhadap rasa nata de coco, Rasa tertinggi diperoleh pada konsentrasi air jeruk lemon $0 \%$ dengan penilaian panelis 4,65 (sedikit asam hingga hambar) karena tidak diberikan air jeruk lemon sehingga dengan perebusan rasa asam dari proses fermentasi nata hilang. rasa terendah oleh panelis pada konsentrasi air jeruk nipis 6\% dengan penilaian 3,64 (agak asam hingga sedikit asam) karena pemberian air jeruk lemon yang lebih tinggi dari yang lain sehingga dengan perebusan tersebut rasa asam air jeruk lemon masih tersisa maka perlunya perebusan dan perendaman yang lebih lama dibandingkan yang lain.

\section{Teknik Analisis Data}

Pengujian dari karakteristik Nata De Coco diperoleh dengan uji Kimia, Uji Fisik, dan Uji Organoleptik, yaitu dimana Uji Kimia adalah mencari dan memperoleh data pH, Kadar Serat, dan Uji Fisik adalah ketebalan, lalu Uji Organoleptik adalah Warna Aroma Rasa dan Tekstur. 
III. HASIL DAN PEMBAHASAN

\begin{tabular}{|c|c|c|c|c|}
\hline $\begin{array}{l}\text { Karakteristik Nata de } \\
\text { Coco }\end{array}$ & \multicolumn{4}{|c|}{$\begin{array}{c}\text { Konsentrasi Jeruk Lemon dan Hasil } \\
\text { Pengamatan }\end{array}$} \\
\hline \multirow[b]{2}{*}{ A. Uji Kimia } & $\mathbf{A}$ & $\mathbf{B}$ & $\mathbf{C}$ & D \\
\hline & $0 \%$ & $2 \%$ & $4 \%$ & $6 \%$ \\
\hline 1. $\mathrm{PH}$ & $5.02 \mathrm{a}$ & $4.55 \mathrm{~b}$ & $3.97 \mathrm{c}$ & $3.54 \mathrm{~d}$ \\
\hline 2. Kadar Serat & $1.52 \mathrm{~b}$ & $1.97 \mathrm{a}$ & $1.44 \mathrm{c}$ & $1.23 \mathrm{~d}$ \\
\hline \multicolumn{5}{|l|}{ B. Uji Fisik } \\
\hline 1. Ketebalan $(\mathrm{cm})$ & $0.60 \mathrm{~b}$ & $0.98 \mathrm{a}$ & $0.54 \mathrm{c}$ & $0.23 \mathrm{~d}$ \\
\hline \multicolumn{5}{|l|}{ C. Uji Organoleptik } \\
\hline 1. Warna & $4.09 a$ & $4.45 \mathrm{a}$ & $3.75 \mathrm{~b}$ & $3.60 \mathrm{~b}$ \\
\hline 2. Aroma & $2.80 \mathrm{c}$ & $4.22 \mathrm{~b}$ & $4.46 \mathrm{a}$ & $4.69 \mathrm{a}$ \\
\hline 3. Rasa & $4.65 \mathrm{a}$ & $4.54 \mathrm{a}$ & $4.20 \mathrm{~b}$ & $3.64 \mathrm{c}$ \\
\hline 4. Tekstur & $3.74 b$ & $4.25 \mathrm{a}$ & $3.65 \mathrm{~b}$ & $2.54 \mathrm{c}$ \\
\hline
\end{tabular}

\section{KESIMPULAN}

Dari Penelitian ini dapat disimpulkan :

1. Pemberian Air jeruk lemon berpengaruh terhadap ketebalan, kadar serat kasar, keasaman $(\mathrm{pH})$ dan organoleptik dari nata de coco.

2. Kualitas nata de coco terbaik diperoleh pada konsentrasi air jeruk nipis $2 \%$ dengan ketebalan $0,98 \mathrm{~cm}$, kadar serat kasar 1,97\%, pH 4,55, dan uji organoleptik terbaik pada tekstur dan warna

\section{DAFTAR PUSTAKA}

Anhar Fajrien Iryandi, Yusuf Hendrawan, Nur Komar. 2014. Pengaruh Penambahan Air Jeruk Nipis (Citrus aurantifolia) dan Lama Fermentasi Terhadap Karakteristik Nata de Soya. Jurnal Bioproses Komoditas Tropis. 1 (1): 8-15. Fakultas Teknologi Pertanian Universitas Brawijaya. Malang.

Elga Marvianie, Yulianti Pratama dan Salafudi. 2014. Fermentasi Sampah Buah Nanas Menggunakan Sistem Kontinu dengan Bantuan Bakteri Acetobacter xylinum. Jurnal Institut Teknologi Nasional. 1 (2):1-11. Fakultas Teknik Sipil dan Perencanaan. Intenas. Bandung.

Saragih, Y. P. 2004. Pembuatan Nata de Coco. Puspa Swarsa. Jakarta. 